\title{
ПРАВОВОЕ РЕГУЛИРОВАНИЕ ДОЛЕВОГО СТРОИТЕЛЬСТВА КОММЕРЧЕСКИХ ОБЪЕКТОВ
}

\section{LEGAL REGULATION OF SHARED CONSTRUCTION OF COMMERCIAL FACILITIES}

\section{A. Ivanov \\ M. Paltseva}

Summary. The article is devoted to the study of the issues of legal regulation of shared construction of commercial real estate objects. Generalization of doctrinal sources allows the author to formulate the concept of "commercial real estate", to identify its main features. Based on the analysis of legislation, law enforcement practice, the author outlines the main stages of the formation of the legal framework for regulating relations in the field of shared construction of commercial real estate objects, identifies resolved issues and identifies some gaps. As a result of the study, the author formulates conclusions and makes recommendations aimed at the legislative definition of terminology and improving the legal status of purchasers of commercial real estate.

Keywords: shared construction, commercial real estate, developer, bankruptcy, equity participation agreement, legal regulation.

\author{
Иванов Алексей Алексеевич \\ Слушатель, Московский университет МВД России \\ имени В.Я. Кикотя \\ ExeleX001@mail.ru \\ Пальцева Маргарита Владимировна \\ Ассистент, МГУ им М.В. Ломоносова
}

Аннотация. Статья посвящена изучению вопросов правового регулирования долевого строительства коммерческих объектов недвижимости. 0бобщение доктринальных источников позволяет автору сформулировать понятие «коммерческая недвижимость», выявить основные его признаки. На основании анализа законодательства, правоприменительной практики, автором обозначаются основные этапы становления правовых основ регулирования отношений в сфере долевого строительства объектов коммерческой недвижимости, обозначаются решенные вопросы и выявляются некоторые пробелы. В результате исследования, автором формулируются выводы и высказываются рекомендации, направленные на законодательное определение терминологии и совершенствование правового статуса приобретателей коммерческой недвижимости.

Ключевые слова: долевое строительство, коммерческая недвижимость, застройщик; банкротство, договор долевого участия, правовое регулирование.

Исследованию термина «коммерческая недвижимость» были посвящены труды таких авторов, как А. Асаул, М.В. Бычкова, О.В. Мезенцева, и других.

М.В. Бычкова в своем исследовании определяет анализируемый термин в качестве объектов недвижимого имущества, предназначенных для систематического долгосрочного извлечения выгоды от их использования другими лицами. [1, с. 90]

Другой автор О.В.Мезенцева, трактует коммерческую недвижимость путем простого перечисления примеров: гаражи для аренды, площади для ритейла (магазины, шоурумы), офисные помещения, объекты предприятий общественного питания, склады, сооружения, иные предприятия имущественного комплекса. $[16$, c. 8]

А. Асаул приводит двухуровневую классификацию объектов коммерческой недвижимости:

1. объекты, приносящие доход их владельцам (гаражи под аренду, торговые объекты, гостиничные комплексы, офисы, развлекательные центры и т.д.). 
2. объекты, способствующие получению дохода на постоянной основе (здания и помещения, предназначенные для логистических операций и складирования товаров, площадки для размещения новых производств и т.д. [13, с. 80]

Обобщение позиций исследователей в области гражданского права приводит нас к выводу о том, что обобщающим признаком для всех объектов коммерческой недвижимости является получение доходов собственником от ее использования иными лицами, а также, от инвестиционных доходов, связанных с повышением рыночной стоимости данных объектов. Особым видом коммерческой недвижимости является сравнительно новая для российского правопорядка категория «апартаменты».

Основным нормативным документом в сфере защиты прав участников общественных отношений, связанных с долевым строительством коммерческих объектов недвижимости (наряду с жилыми и иными нежилыми) является принятый в 2004 году Федеральный закон «Об участии в долевом строительстве многоквартирных домов и иных объектов недвижимости и о внесении изменений в некоторые законодательные акты Российской Федерации» № 214-Ф3 (Далее - Ф3 № 214). [1]

Анализируя текст Ф3 № 214 через призму сравнения условий строительства коммерческих и жилых объектов недвижимости, мы наблюдаем следующие тенденции. Во-первых, контроль за процессом строительства коммерческой недвижимости регламентирован не так строго, как при строительстве, например, многоэтажных жилых зданий. Во-вторых, коммерческие объекты имеют ряд преимуществ, связанных с либеральной регламентацией санитарных норм, архитектурных требований по планировке и шумоизоляции зданий и помещений, а также требований, связанных с развитостью инфраструктурных объектов, характерных для жилой недвижимости (школы, детские сады и площадки, объекты здравоохранения, магазины и т.д.). В-третьих, в законодательстве отсутствуют запреты на строительство объектов коммерческой недвижимости вблизи опасных или шумных производств.

С 2016 года в Ф3 № 214 методично вносились изменения, детализирующие особые требования к застройщикам, порядку привлечения денежных средств в долевое строительство, установлением жесткого контроля над средствами застройщиков и вовлечением в данный процесс институтов банковской системы. Тем не менее, проблема защиты прав дольщиков является актуальной как в отношении жилых помещений, так и применительно к объектам коммерческой недвижимости.
Основным инструментом, опосредуемым отношения, связанные с привлечением инвестиций в объекты коммерческой недвижимости, является договор участия в долевом строительстве (далее - ДДУ). Кроме того, ДДУ является одним из двух допустимых способов привлечения денежных средств граждан для строительства, предусмотренным в п. 2 ст. 1 Ф3 № 214 и основанием для защиты их прав и законных интересов.

В ст. 2 Ф3 № 214 устанавливается понятие застройщика, как основного субъекта долевого строительства. Кроме того, в п. 2 ст. 3 Ф3 № 214 установлен исчерпывающий список законодательных требований к хозяйственным обществам для осуществления деятельности по строительству объектов жилой и коммерческой недвижимости с использованием инструментов привлечения денежных средств субъектов долевого строительства. При этом, сопоставление норм п.п. 1 и 2 ст. 2 Ф3 № 214 свидетельствует о том, что закон не наделяет застройщиков правом строительства объектов недвижимости производственного назначения.

Анализируя права и обязанности сторон ДДУ, предусмотренные в Ф3 № 214 следует отметить, что закон в первую очередь направлен на защиту прав граждан, вложивших свои денежные средства в долевое строительство, что усиливает их позицию, по сравнению с другими участниками соответствующих договорных отношений. Учитывая специфику субъектов ДДУ при строительстве объектов коммерческой недвижимости, а именно то, что его сторонами являются лица, осуществляющие предпринимательскую деятельность, необходимо проанализировать нормы Ф3 № 214 применительно к отношениям с нежилыми объектами недвижимости коммерческого назначения.

Обязательным условием действительности дДУ является его государственная регистрация, производимая на основании норм ст. 48 Федерального закона № 218-Ф3 от 13.07.2015 г. [2] До государственной регистрации ДДУ застройщик не вправе привлекать денежные средства граждан для строительства, что на практике вызывает опасения у многих предпринимателей. Тем не менее, сопоставление норм п.п. 2, 2.1, 2.2 ст. 1 Ф3 № 214, свидетельствует о том, что привлечение денежных средств в строительство объектов коммерческой недвижимости до государственной регистрации ДДУ от иных инвесторов законом не ограничено.

В 2015 году были внесены изменения в п. 3 ст. 433 ГК РФ, распространившие положения о моменте заключения договора, подлежащего государственной регистрации на третьих лиц. [7] Это положение свидетельствует о том, что обязанности участников ДДУ возникают с момента его подписания, а у третьих лиц 
обязанности по его исполнению определяются только после государственной регистрации в специальном реестре. Тем самым, законодатель предоставил застройщику возможность привлечения инвестирования в строительство коммерческих объектов недвижимости путем заключения ДДУ в том числе и до его государственной регистрации. В случае возникновения недобросовестных действий со стороны контрагента по ДДУ, последний не сможет ссылаться на признание договора незаключенным.

Не менее важными на практике представляются вопросы установления размера пени за несвоевременную передачу застройщиком объектов коммерческой недвижимости при долевом строительстве. В п. 2 ст. 6 Ф3 № 214 установлена обязанность уплаты застройщиком пени в размере 1/300 ставки рефинансирования ЦБ РФ за каждый день просрочки, а при участии в долевом строительстве граждан, для них размер пени составляет 1/150 ставки. В данном случае, императивное содержание указанной нормы не позволяет участникам Дду установить другой размер неустойки. Тем не менее, в судебной практике выработан подход [9], согласно которому императивно установленные размеры неустойки могут быть изменены только в сторону увеличения. По нашему мнению, данные правила могут быть применимы при долевом строительстве как объектов жилой, так и коммерческой недвижимости.

На основании положений п. 3 ст. 13 Ф3 № 214 с момента государственной регистрации ДДУ в залоге участников строительства находятся как сам земельный участок (или право на него), так и строящийся на нем объект недвижимости. Данное правило распространяется на все виды недвижимого имущества (в том числе, коммерческого) и всех субъектов, имеющих право участвовать в ДДУ (в том числе, граждан и юридических лиц). Обозначенная норма имеет особое значение, поскольку она является правовым препятствием в продаже недобросовестным застройщиком объект долевого строительства третьим лицам без согласия всех участников ДДУ. Даже при регистрации перехода прав в Росреестре по сделке, при которой имело место нарушение данного запрета, участник долевого строительства имеет право на оспаривание такой сделки и на судебное требование предмета договора от застройщика.

В положениях п. 1 ст. 15.1 и п. 1 ст. 15.2. Ф3 № 214 предусмотрены дополнительные инструменты для обеспечения застройщиком обязательства по ДДУ на объекты жилой недвижимости. Речь идет о требованиях о поручительстве или страховании гражданской ответственности. Однако в отношении коммерческой недвижимости таких требований не установлено, что дает застройщикам дополнительные свободы в выборе субъектов обеспечения обязательств по ДДУ, а также, позволяет им сократить расходы на страхование (поручительство), снизив при этом конечную стоимость объекта долевого строительства.

Отдельным вопросом восстановления прав лиц, участвующих в долевом строительстве, является банкротство застройщика объектов коммерческой недвижимости. Как известно, в связи с изменениями [3], внесенными в июле 2011 года в Ф3 № 127 «О несостоятельности (банкротстве)» [4], в отечественном законодательстве и арбитражной практике была установлена новая категория «банкротство застройщика».

Давая общую характеристику делам в связи с банкротством застройщиков, следует отметить, что в них осуществляется переход к конкурсному производству без этапов наблюдения и санации. Кроме того, установлены некоторые особенности, связанные с ведением специального реестра требований о передаче жилых помещений, или, например, связанные с реализацией имущества застройщика, признаваемого банкротом.

В начале 2019 г. на уровне судебной практики Высшего судебного органа РФ были даны некоторые разъяснения относительно статуса и особенностей защиты прав участников долевого строительства нежилой недвижимости. Верховным судом были в некотором смысле уравнены в статусе участники долевого строительства жилых и коммерческих объектов недвижимости, признано, что их денежные требования к застройщикам, признаваемым банкротом автоматически признаются состоятельными вне зависимости от их судебного подтверждения и стадии, на которой их строительство было приостановлено. [10]

В контексте настоящего исследования следует обратиться к судебной практике, имевшей место в 2018 году, где судами признавалось только право граждан и юридических лиц - покупателей коммерческой недвижимости на получение компенсации за соответствующие объекты, а не на получение их в натуре. Такая позиция занималась арбитражными судами по причине того, что в соответствии с Законом о банкротстве, за покупателями коммерческой недвижимости не закреплялся статус участника долевого строительства. Такая практика приводила к затруднениям в получении приобретателями коммерческой недвижимости денежной компенсации с застройщиков, поскольку приоритетными считались требования лиц, которые приобрели именно жилые помещения.

Данный законодательный пробел был устранен в 2018 году с принятием Федерального закона № 478- 
Ф3. [5] Таким образом, в ситуации с банкротством застройщика физические и юридические лица - приобретатели коммерческой недвижимости получили статус участника долевого строительства, наряду с собственниками жилых помещений, что дало им право, как на денежную компенсацию, так и на получение объектов недвижимости.

На данном этапе, казалось бы, что проблемы неравенства субъектов долевого строительства разрешены, однако в июне 2019 года был принят Ф3 № 151 «О внесении изменений в Федеральный закон «Об участии в долевом строительстве многоквартирных домов и иных объектов недвижимости и о внесении изменений в некоторые законодательные акты Российской Федерации» и отдельные законодательные акты Российской Федерации» [6], в котором были регламентированы многие вопросы завершения строительства объектов застройщиками, признаваемыми банкротами. Однако, этим же нормативным правовым актом юридические лица были вновь выведены из статуса участников долевого строительства и лишены права получения в собственность коммерческих объектов.

Следующим нормативным правовым актом, направленным на защиту прав участников долевого строительства, является принятый в июле 2020 года Федеральный закон № 202 «О внесении изменений в Федеральный закон «Об участии в долевом строительстве многоквартирных домов и иных объектов недвижимости и о внесении изменений в некоторые законодательные акты Российской Федерации» и отдельные законодательные акты Российской Федерации». [7] В данном законе были обновлены некоторые правила компенсации участникам долевого строительства, а также момент перевода денежных средств с эскроу-счетов был определен при сдаче объекта в эксплуатацию.

Общий анализ указанных законодательных преобразований свидетельствует о смещении законодателем приоритета защиты прав участников долевого строительства в сторону приобретателей жилой недвижимости. Однако, за пределами законодательного внимания остались аналогичные вопросы в отношении долевого строительства коммерческой недвижимости.

Представляется, что на сегодняшний день участники долевого строительства объектов коммерческой недвижимости могут включать свои требования, обеспеченные залоговыми обязательствами в специальный реестр и ожидать дальнейших расчетов за счет конкурсной массы застройщика-банкрота. Однако формирование данной массы - процесс, который может затянуться на довольно длительный промежуток времени, либо не сформироваться вообще.
Кроме того, набирает оборот и рассмотрение вопроса о восстановлении прав обманутых приобретателей коммерческой недвижимости, например, апартаментов. Решение указанного вопроса действительно важно, однако приоритетным направлением в настоящее время все же является разрешение в полном объеме вопросов завершения строительства проблемных жилых объектов. В случае успешности, положительной динамики его развития вполне допустимым выглядит и введение проектного финансирования, и использование эскроу-счетов при строительстве коммерческой недвижимости.

Подводя итог настоящему исследованию, отметим, что в настоящее время в условиях повышения привлекательности российского рынка коммерческой недвижимости [15], для обеспечения инвестиционной привлекательности данных объектов отечественному законодателю необходимо восстановить баланс прав участников долевого строительства. Полагаем, что ключевым инструментом привлечения денежных средств в строительство коммерческих объектов недвижимости еще долго будет являться ДДУ, который имеет особую правовую конструкцию и индивидуальные признаки в зависимости от его сторон и их правового статуса.

В этой связи, считаем возможным дать некоторые рекомендации, направленные на совершенствование законодательства.

Во-первых, представляется важным определить законодательно термин «коммерческая недвижимость», с учетом авторских соображений, представленных в настоящем исследовании. При этом, считаем возможным проведение классификации коммерческой недвижимости в зависимости от целевого предназначения строящихся объектов, их расположения и иных факторов. В отдельную категорию коммерческой недвижимости целесообразно вывести апартаменты. Считаем, что такая классификация будет способствовать уравнению в правах участников долевого строительства жилых и нежилых объектов недвижимости;

Во-вторых, возможно дополнение закона о банкротстве нормами, сохраняющими за инвесторами в объекты коммерческой недвижимости права на их получение в натуре при принятии решения о достройке объекта после признания застройщика банкротом.

Представляется, что предложенные в настоящем исследовании изменения и дополнения в законодательство могут повысить эффективность механизма обеспечения прав участников долевого строительства коммерческих объектов наравне с приобретателями жилой недвижимости. 


\section{ЛИТЕРАТУРА}

1. Федеральный закон от 30.12.2004 N214-Ф3 (ред. от 30.04.2021) «0б участии в долевом строительстве многоквартирных домов и иных объектов недвижимости и о внесении изменений в некоторые законодательные акты Российской Федерации» [Электронный ресурс] // Доступ: СПС «КонсультантПлюс Проф» (Дата обращения: 16.06.2021).

2. Федеральный закон от 13.07.2015 N218-Ф3 (ред. от 30.04.2021) «0 государственной регистрации недвижимости» [Электронный ресурс] // Доступ СПС «КонсультантПлюс Проф» (Дата обращения: 17.06.2021).

3. Федеральный закон от 12.07.2011 N210-Ф3 (ред. от 29.07.2017) «0 внесении изменений в Федеральный закон «0 несостоятельности (банкротстве)» и статьи 17 и 223 Арбитражного процессуального кодекса Российской Федерации в части установления особенностей банкротства застройщиков, привлекавших денежные средства участников строительства» [Электронный ресурс] // СПС «КонсультантПлюс Проф» (Дата 0бращения: 16.06.2021).

4. Федеральный закон «0 несостоятельности (банкротстве)» от 26.10.2002 N127-Ф3 (ред. от 20.04.2021) [Электронный ресурс] // СПС «КонсультантПлюс Проф» (Дата обращения: 18.06.2021).

5. Федеральный закон от 25 декабря 2018 г. N478-Ф3 (в ред. от 27.06.2019) «0 внесении изменений в Федеральный закон «06 участии в долевом строительстве многоквартирных домов и иных объектов недвижимости и о внесении изменений в некоторые законодательные акты Российской Федерации» и отдельные законодательные акты Российской Федерации» // С3 РФ. 2018. N53 (часть І). Ст. 8404.

6. Федеральный закон от 27 июня 2019 г. 151-Ф3 (в ред. от 02.08.2019) «0 внесении изменений в Федеральный закон «06 участии в долевом строительстве многоквартирных домов и иных объектов недвижимости и о внесении изменений в некоторые законодательные акты Российской Федерации» и отдельные законодательные акты Российской Федерации» // СЗ РФ. 2019. 26. Ст. 3317.

7. Федеральный закон от 08.03.2015 N42-Ф3 «0 внесении изменений в часть первую Гражданского кодекса Российской Федерации» [Электронный ресурс] // СПС «КонсультантПлюс Проф» (Дата обращения: 01.07.2021).

8. Федеральный закон от 13.07.2020 N202-Ф3 «0 внесении изменений в Федеральный закон «0б участии в долевом строительстве многоквартирных домов и иных объектов недвижимости и о внесении изменений в некоторые законодательные акты Российской Федерации» и отдельные законодательные акты Российской Федерации» [Электронный ресурс] // СПС «КонсультантПлюс Проф» (Дата обращения: 01.07.2021).

9. Обзор практики разрешения судами споров, возникающих в связи с участием граждан в долевом строительстве многоквартирных домов и иных объектов недвижимости (утв. Президиумом Верховного Суда РФ 04.12.2013) (ред. 0т 04.03.2015) [Электронный ресурс] // Доступ: СПС «КонсультантПлюс Проф» (Дата обращения: 16.06.2021).

10. Определение Судебной коллегии по экономическим спорам Верховного Суда РФ от 14 февраля 2019 г. N308-ЭС18-15980 по делу N A53-7967/2017 // СПС «КонсультантПлюс».

11. Определение Верховного Суда РФ от 05.02.2020 N308-ЭС19-26492 по делу N A53-30005/2017. Документ опубликован не был. [Электронный ресурс] // СПС «КонсультантПлюс Проф» (Дата обращения: 01.07.2021).

12. Определение Верховного Суда РФ от 05.11.2019 N309-ЭС19-20126 по делу N A50-30591/2018. Документ опубликован не был. [Электронный ресурс] // СПС «КонсультантПлюс Проф» (Дата обращения: 01.07.2021).

13. Асаул А. Экономика недвижимости: учебник для вузов / А. Асаул. — СПб.: Питер, 2013.— 416 с.с. 80.

14. Бычкова М.В. Исследование понятия «Коммерческая недвижимость» / М.В. Бычкова // Имущественные отношения в РФ.— 2009.— № 4(91).C. 86-91.

15. Итоги рынка коммерческой недвижимости. Коммерсантъ [Электронный ресурс] // Доступ: https://www.kommersant.ru/conference/740 (Дата обращения: 18.06.2021).

16. Мезенцева 0.В. Оценка коммерческой недвижимости: учебное пособие / 0.В. Мезенцева.—Екатеринбург: УрФу, 2011. — 115 с.

( ) Иванов Алексей Алексеевич, ( ExeleX001@mail.ru ), Пальцева Маргарита Владимировна.

Журнал «Современная наука: актуальные проблемы теории и практики» 